\title{
Justification of parameters and technology of retaining prism filling to eliminate landslide
}

\author{
Valery Balakhnin ${ }^{1, *}$, Olga Veretennikova $^{1}$, Roman Pobegaylo ${ }^{1}$, and Ekaterina Mezina ${ }^{1}$ \\ ${ }^{1}$ Prokopyevsk Mining and Design Institute, 650036 Kemerovo, Lenina Avenue 90/5, Russian \\ Federation
}

\begin{abstract}
The process of dumping on the surface mining is one of the most problematic in terms of industrial safety. The problem is compounded by the fact that the external dumps are often pilled on unprepared base, composed of clay. Therefore, such a situation occurs when a set of external factors leads to considerable deformations of the dumps. In particular, a few years ago on one of Kuzbass open pits there was a major landslide. According to the studies made, the reasons for the landslide were irregularities in the process of stacking, intensive snow melting and continuous heavy rains. All this together led to the deformation of the slope of the lower tiers of the outer dump and to the landslides. This article describes the measures of eliminating the danger zone, designed to prevent further landslides and to ensure safe mining works on external dump. The parameters of grounded prism are discussed and the technology of its piling is offered.
\end{abstract}

\section{Materials and Methods}

The formation of dump was carried out in two stages along the ravine's slope with the dip angle of $4-6^{\circ}$. The lower tier of the dump is mostly formed with Quaternary sediments - the loam. During the formation of external dump of overburden some technological errors were made. It was found that the lower tier of the external waste dump was formed with the rocks of Quaternary sediments due to lack of bedrock, which did not provide the desired safety factor during the period of intensive snow melting and long-lasted strong rains. It led to the deformation with landslides from the north-east slope of the lower tier. On the front of the dump the deformation processes were observed, expressed in the form of sliding rock mass on the contact of the slope with a dump's base (plantar landslide). Landslide body was formed at an angle close to the angle of the dump base $\left(6-10^{\circ}\right)$. From the foregoing we concluded that the main causes of deformation processes are the following:

1) The reduction of structural characteristics and loss of load bearing capacity by the dump's base as a consequence. The main reason for the loss of load bearing capacity by dump's base rock is the increase in its water-content under the influence of groundwater, with unloading of the ravine's thalweg [1-3].

2) Dip angle of the base (1-5 $\left.{ }^{\circ}\right)$ congruent to the slope angle and insufficient mechanical strength characteristics of the rock of the dump's base composed of soft Quaternary sediments [4-5].

\footnotetext{
* Corresponding author: v.v.balakhnin@pgpi.su
} 


\section{Results and Discussion}

The criteria for assessing the slopes' sustainability are complying with the conditions of equilibrium of driving and resisting forces, expressed by the G.L. Fisenko formula (1):

$$
n=\frac{\sum F_{r f}}{\sum F_{d f}},
$$

where $\mathrm{n}$ - the safety factor; $\sum F_{r f}$ - resisting forces; $\sum F_{d f}-$ driving forces.

It is known that for assessing the stability of dumps the safety factor should be at least 1.2. At lower value of the safety factor the landslides may occur when the dump is standing without updating more than 1 year. It is possible to reduce the impact of adverse factors and to ensure overburden dump's slopes stability with implementing organizational and technical measures including drainage of the dump's base and loading the lower tier by retaining prism. Calculations have shown that in this case the safety factor is $n \geq 1.2$.

Figure 1 shows the general view of the retaining prism formation along the entire length of the landslide, which at the same time works as drainage trench. Because there is the urgent necessity in rain and melting snow water removing, the retaining prism has been piled of pre-distructed bedrock with high filtration rate. To calculate the parameters of this prism the cross sections of the landslide and the underlying surface were built. After that driving and resisting forces and retaining prism parameters were defined. 


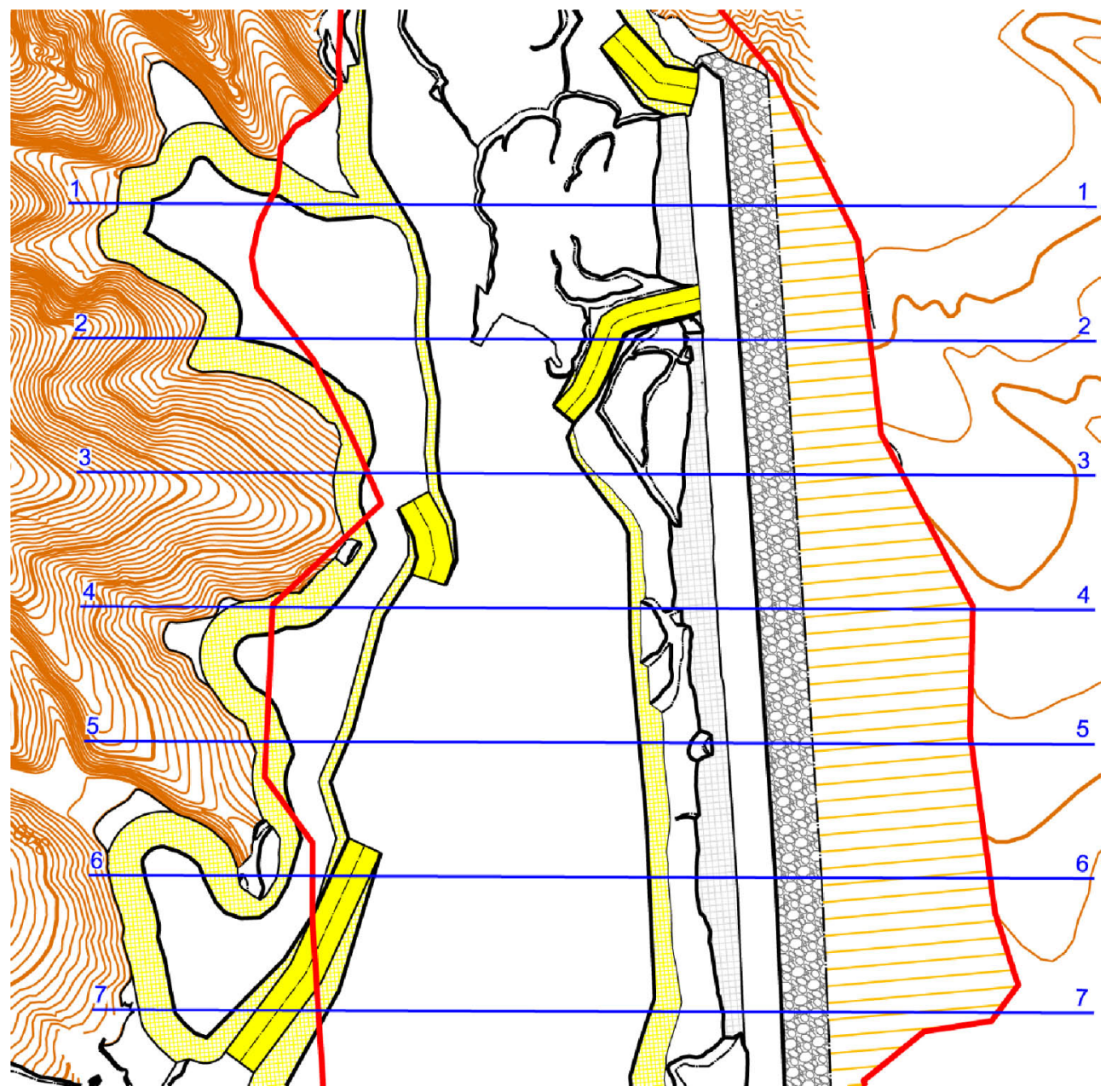

Fig. 1. The scheme of retaining prism formation

Fig. 2 and 3 show examples of cross-sectional areas of the landslide with the calculated parameters of the prism. For the use of hard rock for retaining prism constructing first it is necessary to load the landslide body in vehicles. For this purpose, dragline excavators and dump trucks with carrying are used. The conduit represents a working trench which is conducted by two layers.

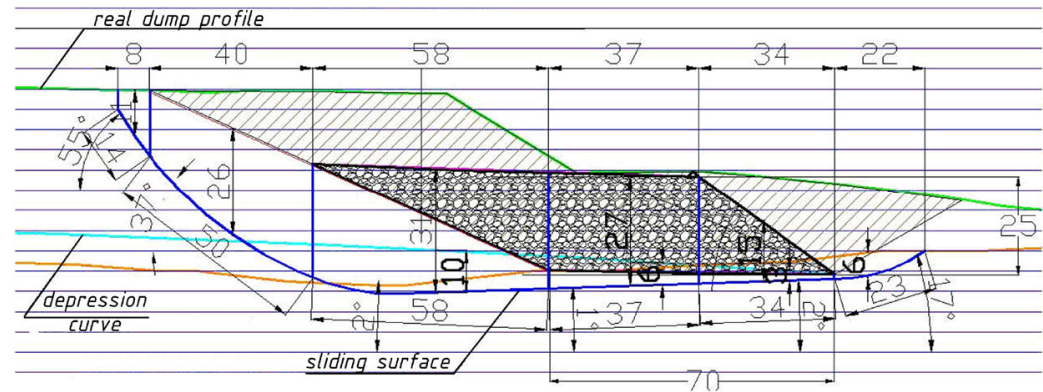

Fig. 2. The scheme of stability calculation of the profile 1-1 


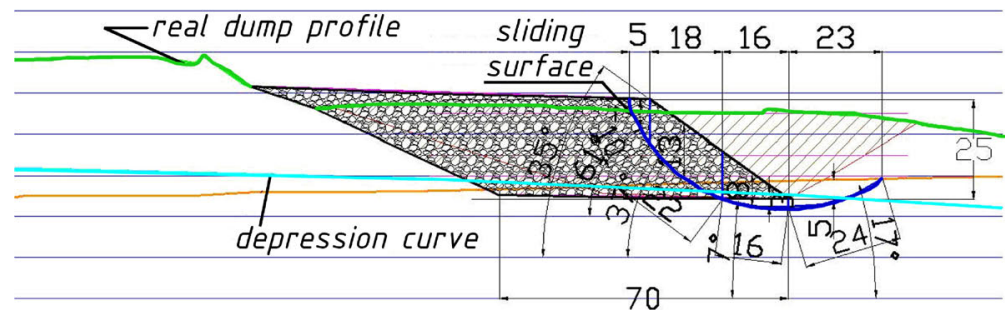

Fig. 3. The scheme of stability calculation of the profile $2-2$

The technological schemes of working the first and the second layers are presented on Fig. 4 and 5. On the figures: $\mathrm{R}_{\mathrm{di}}, \mathrm{R}_{\mathrm{du}}$ - respectively, digging and dumping dragline's radius.

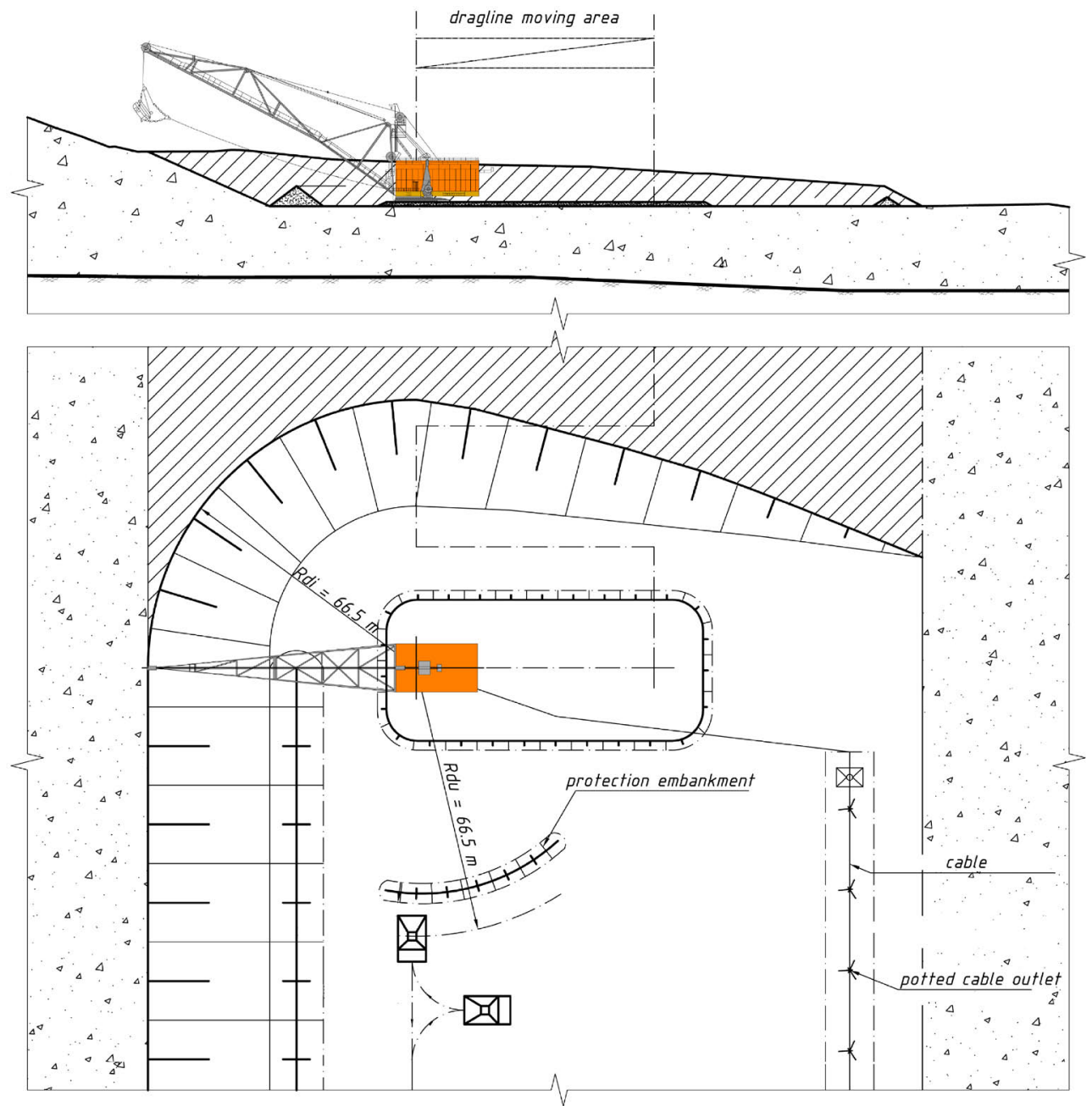

Fig. 4. The $1^{\text {st }}$ layer developing scheme

For developing the second layer we prescribed a simultaneous formation of the retaining prism from bedrock. The height of the retaining prism is $30 \mathrm{~m}$, base width is $70 \mathrm{~m}$. The slope angle is adopted as $20^{\circ}$. 


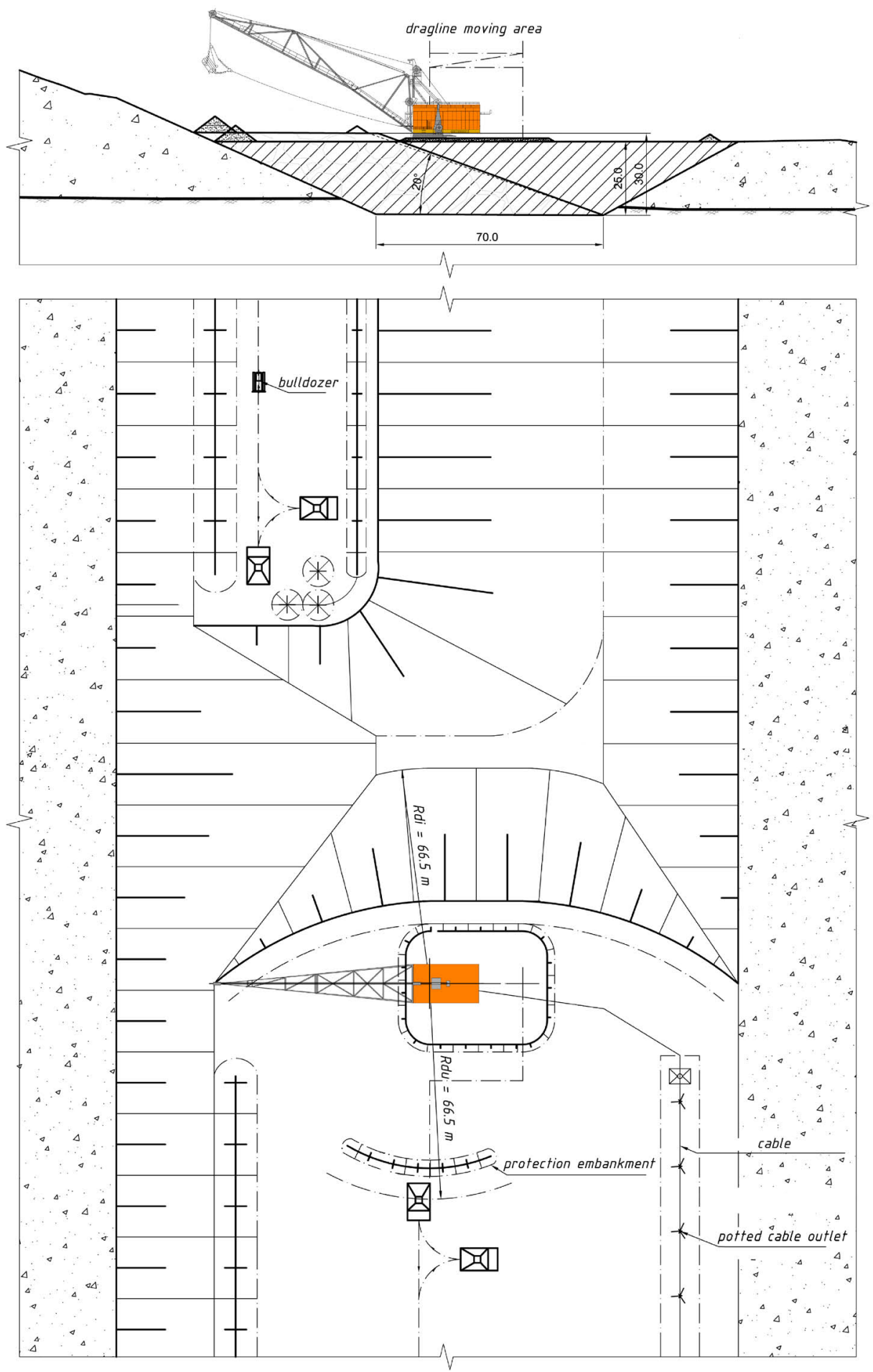

Fig. 5. The technological scheme of the second path of landslide re-excavation by dragline with loading into dump truck 


\section{Conclusion}

The main reason for the deformation processes are the following:

- the structural characteristics reduction and, as a consequence, the loss of bearing capacity by the rocks of the bump's base which consist of $80 \%$ of Quaternary sediments (loams) due to increase in their water content under the influence of groundwater unloading of the ravine's thalweg.

- the angle of the slope, close to the dump's base dip angle (1-5 $\left.{ }^{\circ}\right)$ and soft mechanical characteristics of the base rocks composed of soft Quaternary sediments (mainly loam).

In the areas where landslides of overburden are in decay stage, their further loading (formation overlying dump's tier) without performing the necessary engineering measures (in particular, the drainage performance of the dump's base and piling the retaining prism from the bedrock), can trigger a relapse of overburden deformation processes and a violation of the stability of dump's slopes.

Made research allows developing complex technological schemes the usage of which ensures the landslide excavation with simultaneous formation of retaining prism. This will provide the necessary safety factor, as well as the safety of mining operations.

\section{References}

1. I. Vukotic, V. Kecojevic, W. Zhang, Q. Cai, Int. J. Min. Sci. Tech., 23(6), 901 (2013)

2. M.M. Bereznyak, A.V. Kalinin and V.G. Pronoza, Soviet Mining 6(6), 638 (1970)

3. B. Lokhanov, Y.A. Zakharov, M.M. Bereznyak, A.V. Kalinin, Sov. Min., 3(5), 523 (1967)

4. V. dos Santos, M. O. Medeiros, A. S. D. dos Anjos, C. A. Martínez-Huitle, D. R. da Silva, Chemical Engineering Transactions, 41, 6 (2014)

5. R.Z. Velten, D.C. Lima, M.P.F. Fontes, C.A.B. Carvalho, Soils and Rocks, 32, 11 (2012) 